logos_i_ethos_2017_2_(46), s. 111-128

DOI: http://dx.doi.org/10.15633/lie.2364

Piotr Sawczyński

Uniwersytet Jagielloński w Krakowie

\title{
Dwa wymiary nicości. Gershom Scholem i paradoksy mistyki żydowskiej
}

Każdego, kto postanawia zmierzyć się z imponującą spuścizną Gershoma Scholema, nazywanego najwybitniejszym XX-wiecznym historykiem kabały nawet przez swoich adwersarzy ${ }^{1}$, musi zastanowić w którymś momencie pewien widoczny rozdźwięk. Dlaczego mianowicie Scholem, człowiek o nie-

Piotr Sawczyński - filozof i filolog, doktorant w Katedrze Filozofii Polityki Uniwersytetu Jagiellońskiego oraz junior research fellow na uniwersytetach w Chicago i Nottingham. Autor książki Polityczność podmiotu (Kraków 2016). Publikował m.in. w „Znaku”, „Praktyce Teoretycznej”, „Pressjach” i „Politei”. Przygotowuje rozprawę doktorską poświęconą żydowskim korzeniom podmiotowości politycznej. przeciętnej wrażliwości religijnej, któremu od początku leżała na sercu rehabilitacja żydowskiej mistyki, w żadnej chwili swojego życia nie zdecydował się porzucić teoretyzowania o kabale na rzecz praktykowania jej? Czy powstrzymywał go przed tym jedynie akademicki temperament, chłodny dystans, tak charakterystyczny dla niemieckich intelektualistów żydowskiego pochodzenia, czy też była jakaś inna przyczyna?

Ciekawy trop do rozważań na ten temat zdaje się podsuwać krótki fragment, zatytułowany - osobliwie jak na dziejopisa - Dziesięć ahistorycznych tez o kabale ${ }^{2}$. Ten opublikowany pod koniec lat 50. tekst jest istotny zarówno ze względu na jego zawartość treściową, jak i intrygującą formę. Scholem, znany raczej z zamiłowania do drobiazgowej pracy na

1 Zob. np. M. Idel, Kabała. Nowe perspektywy, tłum. M. Krawczyk, Kraków 2006, s. 40-41.

2 G. Scholem, Dziesięć ahistorycznych tez o kabale, tłum. A. Lipszyc, w: G. Scholem, Żydzi i Niemcy. Eseje, listy, rozmowa, tłum. M. Zawanowska, A. Lipszyc, Sejny 2006, s. 373-381. 
źródłach, daje się w nim bowiem poznać jako niebanalny aforysta, niepokojący czytelnika śmiałymi tezami, pozbawionymi zazwyczaj pogłębionej wykładni. Przywodzi tym samym na myśl głośne Tezy historiozoficzne, napisane w dramatycznym czasie końca lat 30. przez Waltera Benjami$\mathrm{na}^{3}$, przyjaciela i błyskotliwego polemistę Scholema. I choć na pierwszy rzut oka powinowactwo to dotyczy wyłącznie konstrukcji tekstu, w rzeczywistości okazuje się sięgać o wiele głębiej.

Na zakończenie pierwszej z tez Scholem pisze tak: „Autentyczna tradycja [kabała to po hebrajsku właśnie „otrzymana tradycja” - przyp. aut.] pozostaje w ukryciu. Dopiero upadająca tradycja popada w stan przedmiotowy i w tym upadku dopiero widać jej wielkość"4. Prowokuje tym niejednoznacznym ustępem do rozważenia kilku kwestii. Po pierwsze, na czym w kontekście kabały miałby polegać ów upadek? Otóż Scholem wielokrotnie zwracał w swoich pismach uwagę, że większość nowożytnej historiografii żydowskiej nie była bynajmniej, wbrew swoim deklaracjom, bezzałożeniowa. Historię pisano w niej tak, aby wyrugować z żydowskiej pamięci mistycyzm, uważany od czasów haskali za relikt czasów mitycznych, któremu najwyższa pora urządzić niewystawny pogrzeb. W zabiegach tych miała przodować XIX-wieczna Wissenschaft des Judentums, zajmująca się uprawianiem, jak to złośliwie określa Scholem, dziejopisarstwa „drobnomieszczańskiego”, sprofilowanego na potrzeby liberalnego niemieckiego Żyda. Aby pozostać w zgodzie z wymogami naukowości, kabałę eliminowano tam z żydowskiej tradycji religijnej nie tyle poprzez dyskredytację, co przemilczenie, prowadząc do sytuacji, w której „święte księgi przestały promieniować na zewnątrz, zachowując światło tylko w swoim wnętrzu"5.

Choć taka ocena może być przesadzona i krzywdząca ${ }^{6}$, Scholem formułuje ją dobitnie, rozgoryczony widokiem rozkładu kabały, niezdolnej

${ }^{3}$ W. Benjamin, O pojęciu historii, tłum. A. Lipszyc, w: W. Benjamin, Konstelacje. Wybór tekstów, tłum. A. Lipszyc, A. Wołkowicz, Kraków 2012, s. 311-323.

${ }^{4}$ G. Scholem, Dziesięć ahistorycznych tez o kabale, dz. cyt., s. 373.

5 G. Scholem, The Messianic Idea in Judaism, London 1971, s. 307.

${ }_{6}$ Do takiego stanowiska skłania się Moshe Idel, przypominający w swoim studium, że XIX wiek przyniósł przecież wybitną monografię Zoharu autorstwa Adolphe’a Francka (zob. A. Franck, 
już przemówić do swoich adeptów językiem żywego doświadczenia, słyszalnym zapewne wyraźnie w czasach jej świetności. Pochopne byłoby jednak uznanie tej sytuacji za jednoznacznie godną pożałowania. W cytowanym fragmencie jest przecież mowa o jakiejś nieautentyczności tradycji jawnej, która dysponuje wprawdzie własnym, doniosłym głosem, ale $\mathrm{w}$ wypowiadanych odważnie słowach skrywa fałsz. Jak należy to rozumieć? Wydaje się, że chodzi tu Scholemowi o pewną nieprzystawalność przekazywanych treści do medium, w jakim przekaz się dokonuje. Gdyby uznać kabałę żydowską za reprezentatywny przykład mistyki, wówczas pozytywność, jaką należy przypisać jawnemu, swobodnie komunikowalnemu językowi, współgrałaby z „dopełniającym” wydźwiękiem unio mystica. Jednym z głównych zadań, jakie Scholem przed sobą stawia, jest jednak wykazanie, że w żadnej mierze nie powinna ona za taki przykład uchodzić. Zbyt wiele tam pojęć o zaskakująco dużym ładunku negatywności, takich jak nieciągłość, separacja czy resztka. Dlatego właśnie uczynić zadość ontologicznej warstwie kabały można jedynie z perspektywy radykalnego zerwania, które, paradoksalnie, objawia ukrytą w niej głębię znaczeń. Tyle tylko, że zerwana ciągłość obrazów i symboli uniemożliwia eksplorację tej głębi w języku samej kabały, dla współczesnego Żyda stanowiącej zazwyczaj terra incognita.

To rozpoznanie pokazuje, jak sądzę, dlaczego Scholem-historiograf nigdy nie przeobraził się w Scholema-kabalistę, albo, ujmując rzecz nieco bardziej dialektycznie, dlaczego swoją kabałę zdecydował się konsekwentnie uprawiać w dyskursie historycznym. Mówiąc po benjaminowsku, towarzyszyło mu przekonanie o konkretnym „zadaniu” historyka ${ }^{7}$, który za pomocą obcego, pozornie nieprzystającego idiomu, podąża po śladach upadającej tradycji, podejmując się nie tylko jej opisu, ale i próby restauracji. Wykonuje gest swoistej mediacji, dzięki któremu to, co

La Kabbale ou la philosophie religieuse des Hébreux, Paris 1843). Również w obrębie Wissenschaft des Judentums, obok autorów faktycznie kabale niechętnych, takich jak Moritz Steinschneider czy Heinrich Graetz, były również, zdaniem Idela, osoby jej przychylne, np. Nachman Krochmal (zob. M. Idel, Kabała..., dz. cyt., s. 35-40).

7 Por. W. Benjamin, Zadanie tłumacza, tłum. A. Lipszyc, w: W. Benjamin, Konstelacje..., dz. cyt., s. 23-36. 
zapomniane, ma szansę powrócić do życia, choć zawsze pod postacią ledwie dostrzegalnych tropów, spomiędzy których przebija pustka. W tym sensie, „ahistoryczność” w tytule omawianego fragmentu nie sygnalizuje wcale, jak mogło się początkowo wydawać, fenomenologicznego dystansu wobec perspektywy czasowej. Wyraża raczej intuicję, że odpowiedzialny dziejopis nie powinien już dłużej odnosić się do świata kabały jak do historycznej ciągłości, lecz dostrzec w nim kluczowe momenty zerwania. W poszukiwaniu autentyczności trzeba mieć odwagę wychylić się w nicość, tam bowiem może ukrywać się prawda.

Możliwe, że nicość w ogóle należałoby w przypadku historiografii Scholema uznać za kluczowy termin, a jego eksplorację za najważniejsze zadanie historyka żydowskiej kabały. Tak właśnie zakładam na potrzeby dalszych rozważań, w których postaram się wykazać, że universum kabały można zasadnie odczytywać jako tytułowe „dwa wymiary nicości”, odpowiadające pojęciom stworzenia i objawienia, które Scholem uznaje za ośrodkowe dla judaizmu ${ }^{8}$. Karkołomne byłoby oczywiście twierdzenie, że jedną chwytliwą frazą można oddać historyczne zróżnicowanie kabały; co więcej, zastosowanie pojęcia nicości jako klucza interpretacyjnego w przypadku wielu szkół kabalistycznych stanowi jawne nadużycie. Twierdzę natomiast, że może być ono, zwłaszcza w dialektycznym związku z pojęciem języka, tym, co faktycznie charakteryzuje przynajmniej jedną z nich - XVI-wieczną kabałę Izaaka Lurii i jego uczniów, dla Scholema najdojrzalszą ze szkół, obdarzoną przy tym największym ładunkiem filozoficznej spekulacji ${ }^{9}$. O ile w przypadku lurianizmu pojęcie nicości pojawia się przede wszystkim w kontekście stworzenia, o tyle o nicości objawienia Scholem mówi, odwołując się do twórczości Franza Kafki,

8 Zob. G. Scholem, O podstawowych pojęciach judaizmu, tłum. J. Zychowicz, Warszawa 2015.

9 Z uwagi na brak miejsca nie jest niestety możliwe przedstawienie tutaj społecznego i historycznego kontekstu, w jakim rozwijała się w XVI wieku w Safedzie kabała luriańska. Podobnie, zmuszony jestem zrezygnować $\mathrm{z}$ opisu przemian, jakie dokonywały się w niej na przestrzeni lat i modyfikacji, wprowadzanych do doktryny przez uczniów Lurii. Zainteresowanych mogę odesłać do wydanych po polsku pism Scholema (najdokładniejsze informacje zawiera jego opus magnum: G. Scholem, Mistycyzm żydowski i jego główne kierunki, tłum. I. Kania, Warszawa 2007) oraz anglojęzycznych opracowań, z których wyróżnia się praca Shaula Magida (zob. S. Magid, From Metaphysics to Midrash: Myth, History and the Interpretation of Scripture in Lurianic Kabbala, Bloomington 2008). 
którą dyskutował we frapującej korespondencji prowadzonej z Benjaminem. Postaram się zatem wykazać - $\mathrm{z}$ „nieustającym odniesieniem” do Lurii i Kafki - że sprawiedliwość myśli Scholema można oddać najpełniej poprzez zestawienie „podstawowych pojęć judaizmu” z nicością, a w konsekwencji, poprzez mówienie zarówno o nicości stworzenia, jak i nicości objawienia. Jest to, oczywiście, wysoce paradoksalnym osadzeniem słów przesyconych semantyczną pozytywnością w nihilizującym kontekście, ale i szansą na ukazanie Scholema jako nietuzinkowego interpretatora tradycji.

\section{Nicość stworzenia}

Mniej zaskakujące powinno być, na dobrą sprawę, mówienie o nicości w kontekście stworzenia. Dla każdego, kto obraca się w kręgu kultury judeochrześcijańskiej, creatio ex nihilo to przecież biblijny dogmat, uchodzący dodatkowo za kluczową cechę odróżniającą kosmologię żydowską od greckiej. Dla Greków, przekonanych, że nihil ex nihilo fit, materia świata $\mathrm{z}$ konieczności musiała istnieć odwiecznie, zaś ingerencja demiurga służyła jedynie uformowaniu jej, aby pierwotny chaos przekształcił się w metafizyczny porządek ${ }^{10}$. Natomiast dla ortodoksyjnych Żydów wieczny może być tylko Bóg, najdoskonalszy z bytów, a przyznanie tego atrybutu jakiemukolwiek innemu bytowi jest jawną herezją. Świat powstaje z niczego, wolną decyzją Stwórcy, przez co jest nie tylko historyczny, ale również przygodny i niesamodzielny. Tyle tylko, że w dalekiej od ortodoksji kabale rzecz ma się zazwyczaj zgoła odmiennie. Scholem twierdzi wręcz, że można ją określać jako przekorną próbę restytucji greckiego sposobu myślenia w samym sercu judaizmu. Inspiracje neoplatońskie faktycznie stanowią wyznacznik wielu szkół kabalistycznych, które prześcigają się w obrazach tego, jak pierwotnie nieokreślone Ein-Sof rozprzestrzenia swoje życiodajne potencje na coraz dalsze sfery bytu. Scholem uważa zresztą ten flirt z emanacjonizmem za „prawdziwe nieszczęście kabały”,

10 Zob. Arystoteles, Metafizyka, tłum. K. Leśniak, Warszawa 2009, IV, 5 (1009 a), s. 81-82; Platon, Timajos, w: Platon, Dialogi, t. 2, tłum. W. Witwicki, Kęty 2005, s. 657n.

11 G. Scholem, Dziesięć ahistorycznych tez o kabale, dz. cyt., s. 377. 
grożące regresem do idiomu mitycznego, od początku mozolnie przez żydowski monoteizm rugowanego.

Doktryna Lurii wyróżnia się na tle żydowskiej kabały tym, że nie kwestionuje stworzenia $\mathrm{z}$ niczego, odmawia natomiast przejścia do porządku dziennego nad jego daleko idącą nieoczywistością, w tradycji rabinicznej zbywaną jako dogmat, który należy przyjąć na wiarę. Nieoczywistość tę Scholem formułuje następująco: „Jak [...] pogodzić się z myślą, że poza Boską substancją, która stanowi w sobie byt doskonały, ens purissimum, może jeszcze istnieć byt niedoskonały i stworzony, skoro bierze się na serio myśl o doskonałości Boskiej istoty?”"12. Można wyodrębnić tutaj dwa wątki. Po pierwsze, gdyby nicość nie istniała jako coś zewnętrznego wobec boskiej pełni, wszelkie stworzenie mogłoby powstać jedynie poprzez wyemanowanie go z głębi Ein-Sof. To oznaczałoby, że między bytem boskim i nie-boskim nie istnieje żaden moment separujący, a żydowski monoteizm ześlizguje się niebezpiecznie $\mathrm{w}$ rejony panteistyczne ${ }^{13}$. Po drugie jednak, gdyby nicość od początku współistniała z Bogiem, „czekając", aż Ten w akcie stworzenia wyłoni z niej materię, o jakiejkolwiek boskiej pełni w ogóle nie sposób byłoby mówić. Nicości jako boskiego zewnętrza ani zatem $\mathrm{w}$ judaizmie nie może nie być, ani nie może ona być wieczna. To prowadzi Lurię do paradoksalnego, a zarazem wysoce logicznego wniosku, że stworzenie z nicości musiało być poprzedzone stworzeniem samej nicości.

Kluczowym w tym kontekście pojęciem-obrazem, jakim posługuje się Luria, jest cimcum, ,jedna z najbardziej zdumiewających i dalekosiężnych idei mistycznych, jakie kiedykolwiek sformułowano w kabale"14. Cimcum, w języku hebrajskim tyle, co „kurczenie się”, oznacza tutaj najpierwszy

12 G. Scholem, O podstawowych pojęciach judaizmu, dz. cyt., s. 80.

13 Warto zauważyć, że średniowieczna kabała, choć odrzucała creatio ex nihilo, wielokrotnie mówiła o nicości (Ayin) jako wewnętrznym pierwiastku boskości, który musiał być przez Boga przezwyciężony. Takie rozumienie nicości nie stanowiło jednak alternatywy dla emanacjonizmu; było raczej jego meontologicznym dopełnieniem. Zob. S. Drob, Symbols of the Kabbalah. Philosophical and Psychological Perspectives, Northvale-Jerusalem 2000, s. 88nn.

14 G. Scholem, Mistycyzm żydowski i jego główne kierunki, dz. cyt., s. 288. Luria nie był pierwszym kabalistą, który używał pojęcia cimcum (przed nim robili to choćby Nachmanides i Mojżesz Kordovero), ale pierwszym, u którego nabrało ono centralnego znaczenia. Zdaniem Scholema wiązało 
ruch Boga, którym nie jest wcale tomistyczne processio dei ad extra, lecz - przeciwnie - coś, co kabała określa jako zstąpienie „Z siebie w siebie”, czyli skupienie się Boga jak gdyby w jednym punkcie swojej istoty ${ }^{15}$. Ten osobliwy gest pozwala dopiero wydzielić w pierwotnej pełni wolną przestrzeń (tehiru), stanowiącą później rezerwuar wszelkiego stwarzanego bytu. Problemem, na który zwraca uwagę Scholem, jest jednak niejednoznaczność cimcum, które może konotować zarówno „wycofanie się”, jak i „koncentrację”, czyli pojęcia w swoich konsekwencjach niemal przeciwstawne $^{16}$. Zainspirowany kabalistyką Friedrich Schelling sugerował na przykład w Światowiekach, że ograniczenie przez Boga swojego ontologicznego zakresu nie osłabia jego potencji, lecz ją kondensuje, przydając mu tym samym stwórczej mocy ${ }^{17}$. Taka konotacja, choć semantycznie dopuszczalna, dla Scholema jest jednak wypaczeniem sensu cimcum, które należy interpretować raczej jako wyrzeczenie się przez Boga wszechpotęgi, aby umożliwić zaistnienie innych, względnie autonomicznych bytów. Ów kenotyczny gest stworzenia poprzez autoredukcję stanowi dla niego „jedyną w dziejach naprawdę poważną próbę domyślenia do końca koncepcji creatio ex nihilo"18.

Powtórzmy zatem, że pierwszym spośród wszystkich aktów nie jest u Lurii „wystąpienie” Boga na zewnątrz, jak to było w tradycji biblijnej, lecz Jego samoograniczenie. Dopiero w drugim akcie wypromieniowuje On światło swojej istoty w kierunku tehiru, aby za pośrednictwem nicości mogło dokonać się stworzenie. O tym, że nawet tak „dopełniające”

się to z traumatycznym doświadczeniem wygnania Żydów z Hiszpanii pod koniec XV wieku; zob. G. Scholem, Mistycyzm żydowski i jego główne kierunki, dz. cyt., s. 271-272.

15 Por. G. Scholem, Major Trends in Jewish Mysticism, New York 1995, s. 260-261.

16 Spośród adeptów Lurii, o „wycofaniu się” Boga pisał m.in. Chajim Vital w 'Ec chajim (Drzewie życia), zaś o „koncentracji” - Izreael Sarug w Limmudei 'acilut (Nauce o emanacji).

17 F. W. J. von Schelling, Światowieki. Ułamek z roku 1815, tłum. W. Rymkiewicz, Warszawa 2007; por. J. Habermas, Dialectical Idealism in Transition to Materialism. Schelling's Idea of a Contraction of God and Its Consequences for the Philosophy of History, transl. N. Midgley, J. Norman, w: The New Schelling, eds. J. Norman, A. Welchman, New York 2004, s. 54-55. Warto zaznaczyć, że bezpośrednią inspiracją dla Schellinga nie był Luria, lecz Jakub Böhme, który luriańskie motywy wprowadził do mistyki chrześcijańskiej w mocno zniekształconej postaci.

18 G. Scholem, Mistycyzm żydowski i jego główne kierunki, dz. cyt., s. 290. 
pojęcie jak emanacja ma tutaj nicościujące implikacje, przesądza jednak szewirę (szewirat ha-kelim), najbardziej chyba sugestywny z obrazów, jakimi posługuje się Luria. Sformułowanie to, oznaczające dosłownie „rozbicie naczyń”, symbolizuje fundującą ten świat kosmiczną katastrofę, powodującą wybrakowanie wszystkiego, co w jej następstwie powstaje. Co do tej katastrofy doprowadza? Otóż, aby wszelkie stworzenia były bytami „mocnymi”, obdarzonymi spoistą tożsamością, Bóg lepi naczynia, służące jako formy, w które ma następnie zostać wlane życiodajne boskie światło ${ }^{19}$. Przygotowane na przyjęcie emanacji naczynia okazują się jednak wobec blasku światła życia zbyt kruche, nie wytrzymują boskiej mocy i, popękane, spadają w otchłań, a wraz z nimi rozproszone, migoczące iskry boskości. W rezultacie, jak to ujmuje Scholem, „nic nie jest już tam, gdzie właściwie być powinno. Wszystko znajduje się gdzieś indziej" ${ }^{20}$, a temu rozproszeniu bytów towarzyszy dojmujący deficyt witalności. O ile cimcum było zatem stworzeniem nicości, o tyle szewire można bez wielkiego nadużycia określić jako nicość stworzenia.

Pojawia się oczywiście pytanie, jak do rozbicia naczyń mogło w ogóle dojść. W następstwie cimcum spodziewalibyśmy się przecież po Bogu raczej niedostatku stwórczej mocy, aniżeli jej niekontrolowanego nadmiaru. Chyba, że faktycznie skłaniamy się ku tym odczytaniom cimcum, które widzą w nim wzmożenie boskiej potencji, co Scholem uważa jednak - jak widzieliśmy - za sprzeczne z ogólnym wydźwiękiem doktryny Lurii. Ciekawą, choć mocno spekulatywną wykładnię proponuje w tym kontekście Agata Bielik-Robson, która bada kategorie pojęciowe lurianizmu w odniesieniu do idealizmu niemieckiego. Twierdzi ona, że być może rozbicie naczyń tylko pozornie było błędem Boga, w rzeczywistości stanowiło zaś Jego chytrą strategię. Gdyby naczynia nie rozpadły się, świetlista boska substancja, która po brzegi miała je wypełnić, mogłaby bowiem szybko pochłonąć to, co stworzone, zaprzepaszczając odrębność

19 Zob. G. Scholem, On Jews and Judaism in Crisis. Selected Essays, ed. W. Dannhauser, New York 1976, s. 283-284. Z konieczności dokonuję tu oczywiście daleko idącego uproszczenia owego stwórczego procesu, skupiając się na tych jego elementach, które wydają się kluczowe dla tematu moich rozważań.

${ }^{20}$ G. Scholem, Kabała i jej symbolika, tłum. R. Wojnakowski, Warszawa 2014, s. 162. 
bytów, tak dramatycznie wypracowaną przez Boga w akcie kontrakcji. Być może była to zatem „katastrofa kontrolowana”, pozwalająca przypuszczać, że do ocalenia życiodajnej separacji nawet permanentnie ponawiany gest cimcum nie wystarczy - konieczna jest dodatkowo dekompozycja stworzonego bytu. Zdaniem Bielik-Robson Bóg sugeruje w ten sposób każdemu z bytów, że ich wybrakowanie jest ceną, jaką trzeba zapłacić za pojedyncze istnienie, którym zostały obdarzone ${ }^{21}$. Jeśli tak byłoby naprawdę, metafora bólów porodowych, jaką stosuje w pewnym momencie w kontekście szewiry Scholem ${ }^{22}$, zyskiwałaby głęboki sens.

\section{Nicość objawienia}

Jeszcze bardziej nieoczywisty charakter pojęcie nicości zdradza w kontekście objawienia, bezpośrednio łącząc się przy tym z fenomenem języka. Można wręcz zaryzykować stwierdzenie, że modernistyczna rewizja, jakiej poddaje kabałę Scholem, polega na przeniesieniu luriańskiej doktryny kosmologicznej na płaszczyznę lingwistyki. Nie musi być to oczywiście żadna ekstrawagancja, wszak wielokrotnie wskazywano na doniosłą rolę słowa w judaizmie, a sam Scholem podkreśla, że wyróżnikiem żydowskich kabalistów z grona mistyków było pozytywne wartościowanie przez nich tego, co językowe. Susan A. Handelman w swojej wpływowej pracy The Slayers of Moses, odczytującej żydowskie kategorie pojęciowe przez pryzmat dekonstrukcji, twierdzi nawet, że judaizm nigdy nie musiał wykonywać ruchu, który w XX-wiecznej humanistyce zyskał miano „zwrotu językowego"23. Podczas gdy zarówno grecka, jak i chrześcijańska tradycja myślenia, przejęte później przez większość europejskiej filozofii, opierały się na zasadniczym rozdziale między „słowami i rzeczami", w judaizmie do takiej separacji nigdy nie doszło (ten sam

${ }^{21}$ Zob. A. Bielik-Robson, God of Luria, Hegel, Schelling. The Divine Contraction and the Modern Metaphysics of Finitude, w: Mystical Theology and Continental Philosophy: Interchange in the Wake of God, eds. D. Lewin, S. D. Podmore, D. Williams, London-New York, 2017, s. 41n.

22 Zob. G. Scholem, Mistycyzm żydowski i jego główne kierunki, dz. cyt., s. 296.

${ }_{23}$ Zob. S. A. Handelman, The Slayers of Moses. The Emergence of Rabbinic Interpretation in Modern Literary Theory, Albany 1982, s. 4nn. 
hebrajski termin dawar oznacza zarówno mowę, jak i sprawę, "słowo" i „rzecz”24). Zwłaszcza dla kabalistów rzeczywistość nie była objawiana człowiekowi poprzez medium języka, lecz w samym tym języku, a słowa stanowiły istotę boskiej ekspresji.

Tym, co szczególnie eksponuje Scholem, nie jest jednak wyłącznie językowy charakter żydowskiego objawienia, lecz jego dialektyczne zespolenie z negatywnością, aż do punktu, w którym negatywność przeradza się w nicość. Aby rzetelnie zrekonstruować osobliwość tej myśli, zacznijmy wpierw od przypomnienia dobrze znanego faktu, że judaizm to religia nie obrazu, lecz słowa. Bóg wprawdzie objawia się w niej temu, co stworzone, jednak nic w świecie nie może reprezentować transcendencji. Dlatego właśnie odsłonięcie się Boga ma miejsce w języku, a dodatkowo obwarowane jest bezwzględnym zakazem sporządzania wizerunków. Skąd ten rygorystyczny ikonoklazm? W kontekście tego, jak Bielik-Robson odczytywała proces stworzenia w lurianizmie, komentarz nasuwa się niejako automatycznie. Objawienie, choć konieczne jako drogowskaz etyczny dla człowieka, nade wszystko nie może naruszać życiodajnej separacji, z takim poświęceniem wypracowywanej przez Boga w trakcie cimcum. Wyrazista manifestacja boskości wymuszałaby na człowieku ukorzenie się przed blaskiem jej chwały, a tym samym, nakazywałaby $\mathrm{Mu}$ wyrzeczenie się swojej pojedynczości ${ }^{25}$. Dlatego właśnie w Księdze Wyjścia Jahwe odrzuca prośbę Mojżesza, który pragnie ujrzeć twarz Boga, a następnie chroni go przed jej obezwładniającą mocą: „Gdy będzie przechodzić moja chwała, ukryję Cię w szczelinie skały i osłonię swoją dłonią, dopóki nie przejdzie. Następnie cofnę dłoń i zobaczysz Mnie od tyłu, lecz twarzy mojej nie ujrzysz" (Wj 33, 22-23) ${ }^{26}$. Boskie plecy, odsłonione przed Mojżeszem, symbolizują tu warunkowość żydowskiego

24 Zob. G. Scholem, Name Gottes und die Sprachtheorie der Kabbala, w: G. Scholem, Judaica 3, Frankfurt am Main 1973, s. 34-35.

${ }_{25}$ Obecne u Lurii jest i inne, nieco bardziej trywialne wyjaśnienie: objawienie musi być niepełne w następstwie kontrakcji, która odebrała Bogu zdolność do zamanifestowania siebie w wyrazisty sposób. Zob. L. Fine, Physician of the Soul, Healer of the Cosmos. Isaac Luria and His Kabbalistic Fellowship, Stanford 2003, s. 128n.

26 Por. M. Buber, Mojżesz, tłum. R. Wojnakowski, Warszawa 1998, s. 40-45. 
objawienia, które musi być fragmentaryczne, aby nie wpadło w śmiertelną pułapkę metafizyki obecności. Można wręcz powiedzieć, i do tej konkluzji zdaje się skłaniać Scholem, że jest ono kolejną fazą cimcum, kolejnym epizodem w walce, jaką Bóg stacza z samym sobą o ludzką podmiotowośćc ${ }^{27}$.

Czym wobec tego jest objawienie, jeśli nie ukazaniem człowiekowi świętego oblicza? Czym są boskie „plecy”? Jeśli zgodzimy się, że zapisem żydowskiego objawienia jest Tora, jego językowy charakter powinien być dla nas oczywisty. Myliłby się jednak ten, kto uznałby objawienie za skierowany do człowieka komunikat, a przynajmniej nie powiedziałby całej prawdy. To treści ludzkiego języka, podkreśla Scholem, odnoszą się zawsze do jakiegoś specyficznego kontekstu sensu. W przeciwieństwie do nich język boskiego objawienia jest wprawdzie konkretem, ale „absolutnym", co oznacza, że w swoim przekazie jest wszechobejmujący - nie posiada określonej treści, przekazując raczej w słowie nieskończone bogactwo znaczeń. Tym samym jednak objawienie z perspektywy ludzkiego języka niczego w sposób bezpośredni nie komunikuje, a w konsekwencji, pozbawione jest sensu. Jak to ujmuje Scholem, Bóg „oznajmia siebie pierwotnie w swojej nieskończonej pełni, ale oznajmienie to - i na tym polega cała rzecz - jest niezrozumiałe!”28. Gdyby bowiem było inaczej, to znaczy, gdyby boski język był powszechnie rozumiany, stanowiłby z konieczności domenę tego, co ogólne, podobnie jak dzieje się to z językami, którymi posługują się ludzkie zbiorowości. Tymczasem boski język jest wprawdzie wszechogarniający, lecz zarazem radykalnie pojedynczy, przez co może być zrozumiały nie dla ludzi łącznie, lecz dla każdego człowieka z osobna. Kabaliści wyprowadzili z tego szeroko komentowaną tezę, że Tora zwraca się do każdego człowieka w sposób dla niego przeznaczony i wyłącznie przez niego możliwy do odczytania ${ }^{29}$.

Należy przy tym niemniej zaznaczyć, że zrozumienie sensu boskiego słowa nigdy nie jest możliwe na drodze bezpośredniego wglądu, a jego

27 Zob. G. Scholem, Żydzi i Niemcy..., dz. cyt., s. 309, 347.

28 G. Scholem, O podstawowych pojęciach judaizmu, dz. cyt., s. 151.

29 Zob. G. Scholem, O podstawowych pojecciach judaizmu, dz. cyt., s. 156. 
komunikacyjność odkrywa się dopiero dialektycznie, poprzez zapośredniczenie $w$ tradycji. Niedialektyczna recepcja świętego języka została przez Boga zablokowana, w przeciwnym razie byłaby bowiem dla ludzkiej podmiotowości niszcząca. Objawienie ma zatem dla Żydów charakter wybitnie historyczny, co należy jednak rozumieć odmiennie niż czynią to chrześcijańska ortodoksja (objawienie jako jednorazowe wydarzenie) i mistyka (wydarzenie wielokrotnie ponawiane we własnym wnętrzu). Odsłonięcie się Boga nie w ciele, lecz w języku, przesądza tyleż o zewnętrzności objawienia, co o jego nieuchronnym wybrakowaniu. I choć z każdą próbą odczytania boskie słowo oddziałuje na adepta, to żadne kolejne podejście nie jest prostym powtórzeniem poprzedniego, gdyż żydowskie objawienie nawarstwia się i dopiero w szerokiej perspektywie czasowej może ujawnić swój sens. Wszystko to zdaje się sugerować, że aby w wybrakowanym świecie światło boskiego słowa mogło się stać zrozumiałe, samo musi się załamać w niedoskonałym medium komentarza i przejść tym samym swoistą próbę negatywności.

Żydowska tradycja (kabała) byłaby w tym rozumieniu niczym innym, jak ciągiem fragmentarycznych interpretacji boskiego słowa, często wzajemnie sprzecznych, a jednak produktywnie kumulujących się. Każde kolejne ogniwo w łańcuchu tradycji naznaczone jest wprawdzie „melancholią niedostateczności” ${ }^{30}$, niemniej sam ten łańcuch zdaje się otwierać niemal nieograniczoną przestrzeń do interpretacji. Co jednak, gdy dochodzi do momentu radykalnego zerwania, o którym mówiliśmy na początku? Czy boskie objawienie może zachować żywotność, gdy kabała, będąca zdaniem Scholema jego najcenniejszym medium, znajduje się w stanie rozkładu? Tego między innymi zagadnienia dotyczy frapująca korespondencja, jaką Scholem prowadził z Benjaminem w latach 30. na temat twórczości Kafki ${ }^{31}$. Wielowątkowość i ciężar intelektualny owych

${ }^{30}$ Pozwalam sobie wykorzystać bardzo adekwatne w tym kontekście sformułowanie Adama Lipszyca. Zob. A. Lipszyc, Ślad judaizmu w filozofii XX wieku, Warszawa 2009, s. 79.

31 Słynna wymiana listów między przyjaciółmi nie ograniczała się oczywiście do tego zagadnienia. Pisali oni do siebie regularnie od lat 20. aż do śmierci Benjamina. Reprezentatywny wybór tej korespondencji polscy czytelnicy mogą znaleźć we wspominanym już zbiorze Żydzi i Niemcy w tłumaczeniu i pod redakcją Lipszyca. 
listów domagają się naturalnie oddzielnego opracowania, tutaj poświęcimy natomiast nieco miejsca najbardziej zajmującemu nas zagadnieniu: czy mianowicie objawienie pozbawione medium może nadal zachowywać $\mathrm{w}$ sobie jakiekolwiek znaczenie?

Należy przypuszczać, że kwestia ta nieprzypadkowo pojawia się u Scholema à propos Kafki, którego dzieło niemal w całości można odczytywać jako dramatyczną relację z „punktu zerowego" żydowskiej tradycji, tak ponuro diagnozowanego również przez samego Scholema. Wyzierająca z tej literatury teologiczna wizja współczesności zdaje się być po prostu jedyną, na jaką stać nasze czasy. A jednak odczytanie, jakiemu Scholem poddaje autora Procesu, istotnie problematyzuje ów katastroficzny ton, współgra natomiast ciekawie z przytaczanym już dictum o autentyczności upadającej tradycji. W liście z 20 września 1934 roku Scholem sugeruje mianowicie, że być może kryzys nie wyznacza wcale momentu schyłkowego żydowskiej tradycji, lecz stanowi jej odwieczny horyzont. Innymi słowy, groźba tego, że rozczłonkowane komentarze do objawienia nawarstwią się kiedyś tak ściśle, iż niemożliwością będzie przedarcie się przez ich gąszcz, zdaje się wisieć nad kabałą od samego jej zarania, wyznaczając nieprzekraczalną kondycję żydostwa. Załamanie się byłoby wówczas graniczną, ale niekoniecznie schyłkową fazą tradycjii ${ }^{32}$.

Scholem rozwija tę myśl, odnosząc się do słynnego eseju, jaki poświęcił Kafce Benjamin. W jego końcowych partiach autor Tez historiozoficznych nawiązuje do postaci uczniów, którzy zgubili Pismo, sugerując, że podobnie należałoby u Kafki odczytywać stan, w jakim znajduje się tradycja ${ }^{33}$. Benjamin nie przesądza przy tym, co doprowadziło do owej utraty - czy ciągłość tradycji została umyślnie zerwana (jak to sugerował Scholem), czy też raczej dialektyczna piramida komentarzy runęła pod własnym ciężarem, grzebiąc ukryty w nich gdzieś sens boskich słów. Ważne jest to, że dzieło objawienia zostało bezpowrotnie zaprzepaszczone. Scholem przeciwstawia temu rozpoznaniu paradoksalną konstrukcję,

32 Zob. G. Scholem, Żydzi i Niemcy..., dz. cyt., s. 291.

${ }_{33}$ Zob. W. Benjamin, Franz Kafka. Z okazji dziesiątej rocznicy jego śmierci, tłum. A. Lipszyc, w: W. Benjamin, Konstelacje..., dz. cyt., s. 258. 
którą nazywa „nicością objawienia” i definiuje jako stan, w którym objawienie „obowiązuje, lecz nic nie znaczy”, czyli - innymi słowy - „zostaje zredukowane do zerowego poziomu swojej treści, lecz mimo to nie znika" ${ }^{34}$. Należy przez to rozumieć, jak się zdaje, że krytyczny stan komentarza jako tego medium, przez które przebijać może niewyraźne boskie światło, to stan, w którym światło to nadal bywa dostrzegalne, nie opromienia już jednak żadnych zakamarków sensu. Żydzi nadal pozostają zatem w posiadaniu Pisma, nie potrafią już jednak go rozszyfrować, a co za tym idzie - wypełnic ${ }^{35}$.

Scholem faktycznie dystansuje się tu od Benjamina, ale intencje tego kroku nie są jeszcze do końca jasne. Czyżby sugerował w ten sposób, że nawet w objawieniu sprowadzonym do nicości może kryć się jakaś pozytywność? Wydaje się, że tak właśnie można próbować odczytać jego słowa. Skorzystajmy w tym miejscu raz jeszcze ze spekulacji, jaką snuje Bielik-Robson. Jej zdaniem obietnica pozytywności wynika z faktu, że nawet moment pełnej negatywności ma dla Scholema, przeciwnie niż dla Benjamina, dialektyczny charakter. Ruch dialektyki nie dobiegł wcale końca, nie idzie zatem o próbę przekroczenia nicości, lecz o dostrzeżenie w niej samej możliwości nowego otwarcia ${ }^{36}$. Według Bielik-Robson Scholem rozumuje następująco: im bardziej Bóg wycofuje się ze świata, tym bardziej światu niezbędne jest objawienie. W punkcie najgłębszej negatywności, krańcowej nieobecności Boga, potrzeba ta staje się tak

${ }^{34}$ G. Scholem, Żydzi i Niemcy..., dz. cyt., s. 292, podkreślenie oryginalne.

35 Zasadnicza różnica między Benjaminem i Scholemem zdaje się tkwić właśnie w znaczeniu, jakie przypisują oni objawieniu. Gorzka konstatacja Benjamina, że Pismo zaginęło, nie musi bynajmniej oznaczać, że sytuacja Żydów jest beznadziejna. Jego zdaniem, po „śmierci” objawienia nadal bowiem możliwe jest podejmowane pewnych niepozornych gestów o charakterze mesjańskim, a brak drogowskazu niekoniecznie wymusza działanie „na oślep”. Dla Scholema natomiast religijnie pojmowane objawienie ma daleko większe znaczenie i stanowi warunek sine qua non zbawczej misji. Dlatego właśnie broni on objawienia do ostatka, przekonując, że niemożność rozszyfrowania Pisma nie oznacza, iż zostało ono „zgubione”. Benjamin tymczasem, z irytującą dla Scholema dezynwolturą, stwierdza, że „czy uczniowie je zgubili, czy też nie mogą go rozszyfrować - to wszystko jedno, ponieważ bez właściwego klucza Pismo nie jest już Pismem” (G. Scholem, Żydzi i Niemcy..., dz. cyt., s. 289).

${ }_{36}$ Zob. A. Bielik-Robson, Mysteries of the Promise. Negative Theology in Benjamin and Scholem, w: Negative Theology as Jewish Modernity, ed. M. Fagenblat, Indianapolis 2017, s. 7nn. 
dojmująca, że samo wycofanie się przybiera postać objawienia. Tym samym już nie tylko fragmentaryczne objawienie w języku, ale i nicość powstałą po jego załamaniu się, można byłoby uznać za kolejną - tym razem graniczną - odsłonę cimcum, kryjącą w sobie potencjał jakiejś, niejasnej jeszcze, produktywności ${ }^{37}$. W ramach konkluzji można zatem powiedzieć, że o ile interpretujący Kafkę Benjamin pragnął wyraźnie trzymać się granicy między nihilizmem a religią, o tyle dla Scholema możliwa jest figura „religijnego nihilisty”, który dzięki swej dialektycznej chytrości nawet w stanie skrajnej negatywności nie rezygnuje z poszukiwania tego, co pozytywne ${ }^{38}$.

Czy jednak mówienie o podwójnym ruchu cimcum - uznanie zarówno stworzenia, jak i objawienia za komplementarne odsłony boskiej autoredukcji - nie wygląda w tym kontekście nazbyt frywolnie? Równie dobrze można by przecież odsunąć od siebie pokusę dialektyki i uznać, że ich wybrakowanie to przejaw zwyczajnej boskiej niemocy, a nie zawoalowanego sprytu. Intrygujące teksty Scholema zostawiają nas z takimi właśnie pytaniami, lecz nie może chyba być inaczej, skoro powstawały na chwiejnym fundamencie, jakim jest żydowska tradycja. Być może i my będziemy mieli swój udział w zapełnianiu jej interpretacyjnych luk, choć oczywiście nigdy nie powinniśmy się łudzić, że zdołamy tę pracę dokończyć. Bez względu jednak na to, w jaką stronę podąży nasz komentarz, jedna rzecz wydaje się w przypadku Scholema bezsprzeczna. W jego odczytaniu Lurii i Kafki pojęcie nicości odgrywa mianowicie niepoślednią i wysoce nieoczywistą rolę, produktywnie obecną zarówno w akcie stworzenia, jak i w objawieniu transcendencji. Tym samym, jeśliby chcieć na podstawie lektury Scholema powiedzieć coś o kondycji

37 Zob. A. Bielik-Robson, Mysteries of the Promise..., dz. cyt., s. 8. Por. I. Wohlfarth, Haarscharf auf der Grenze zwischen Religion und Nihilismus. Zum Motiv des Zimzum bez Gershom Scholem, w: Gershom Scholem. Zwischen den Disziplinen, Hrsg. P. Schäfer, G. Smith, Frankfurt am Main 1995, s. 236nn; S. Moses, Gershom Scholem's Reading of Kafka: Literary Criticism and Kabbalah, „New German Critique” 77 (1999), s. 149nn.

38 O możliwości pomyślenia „religijnego nihilizmu” świadczy ustęp z Dziesięciu ahistorycznych tez o kabale, w którym Scholem pisze, że Kafka „w niezrównany sposób” pokazał, na czym polega niejednoznaczna relacja tych dwóch elementów. Zob. G. Scholem, Dziesięć ahistorycznych tez o kabale, dz. cyt., s. 378-379. 
współczesnego żydostwa, należałoby nakreślić obraz nieuchronnego zawieszenia w cieniu nicości, która równie dobrze co niszczyć, może rozniecać wątłe światło ocalenia.

\section{Bibliografia}

Arystoteles, Metafizyka, tłum. K. Leśniak, Warszawa 2009.

Benjamin W., Konstelacje. Wybór tekstów, tłum. A. Lipszyc, A. Wołkowicz, Kraków 2012. Bielik-Robson A., God of Luria, Hegel, Schelling. The Divine Contraction and the Modern Metaphysics of Finitude, w: Mystical Theology and Continental Philosophy: Interchange in the Wake of God, eds. D. Lewin, S. D. Podmore, D. Williams, London-New York, 2017, s. 36-56.

Bielik-Robson A., Mysteries of the Promise. Negative Theology in Benjamin and Scholem, w: Negative Theology as Jewish Modernity, ed. M. Fagenblat, Indianapolis 2017, s. 246-264.

Buber M., Mojżesz, tłum. R. Wojnakowski, Warszawa 1998.

Drob S., Symbols of the Kabbalah. Philosophical and Psychological Perspectives, NorthvaleJerusalem 2000.

Fink L., Physician of the Soul, Healer of the Cosmos. Isaac Luria and His Kabbalistic Fellowship, Stanford 2003.

Franck A., La Kabbale ou la philosophie religieuse des Hébreux, Paris 1843.

Gershom Scholem. Zwischen den Disziplinen, Hrsg. P. Schäfer, G. Smith, Frankfurt am Main 1995.

Habermas J., Dialectical Idealism in Transition to Materialism. Schelling's Idea of a Contraction of God and Its Consequences for the Philosophy of History, transl. N. Midgley, J. Norman, w: The New Schelling, eds. J. Norman, A. Welchman, New York 2004, s. 43-89.

Handelman S. A., The Slayers of Moses. The Emergence of Rabbinic Interpretation in Modern Literary Theory, Albany 1982.

Idel M., Kabała. Nowe perspektywy, tłum. M. Krawczyk, Kraków 2006.

Lipszyc A., Ślad judaizmu w filozofii XX wieku, Warszawa 2009.

Magid S., From Metaphysics to Midrash: Myth, History and the Interpretation of Scripture in Lurianic Kabbala, Bloomington 2008. 
Moses S., Gershom Scholem's Reading of Kafka: Literary Criticism and Kabbalah, „New German Critique" 77 (1999), s. 149-167.

Mystical Theology and Continental Philosophy: Interchange in the Wake of God, eds.

D. Lewin, S. D. Podmore, D. Williams, London-New York 2017.

Negative Theology as Jewish Modernity, ed. M. Fagenblat, Indianapolis 2017.

The New Schelling, eds. J. Norman, A. Welchman, New York 2004.

Platon, Timajos, w: Platon, Dialogi, t. 2, tłum. W. Witwicki, Kęty 2005, s. 657-743.

Schelling F. W. J. von, Światowieki. Ułamek z roku 1815, tłum. W. Rymkiewicz, Warszawa 2007.

Scholem G., Dziesięć ahistorycznych tez o kabale, tłum. A. Lipszyc, w: G. Scholem, Żydzi i Niemcy. Eseje, listy, rozmowa, tłum. M. Zawanowska, A. Lipszyc, Sejny 2006, s. 373-381.

Scholem G., Kabała i jej symbolika, tłum. R. Wojnakowski, Warszawa 2014.

Scholem G., Major Trends in Jewish Mysticism, New York 1995.

Scholem G., Mistycyzm żydowski i jego główne kierunki, tłum. I. Kania, Warszawa 2007.

Scholem G., Name Gottes und die Sprachtheorie der Kabbala, w: G. Scholem, Judaica 3, Frankfurt am Main 1973, s. 7-70.

Scholem G., On Jews and Judaism in Crisis. Selected Essays, ed. W. Dannhauser, New York 1976.

Scholem G., O podstawowych pojęciach judaizmu, tłum. J. Zychowicz, Warszawa 2015.

Scholem G., The Messianic Idea in Judaism, London 1971.

Wohlfarth I., Haarscharf auf der Grenze zwischen Religion und Nihilismus. Zum Motiv des Zimzum bez Gershom Scholem, w: Gershom Scholem. Zwischen den Disziplinen, Hrsg. P. Schäfer, G. Smith, Frankfurt am Main 1995, s. 176-256.

\section{Abstrakt \\ Dwa wymiary nicości. Gershom Scholem i paradoksy mistyki żydowskiej}

Artykuł jest próbą analizy kabalistycznej filozofii Gershoma Scholema w kontekście pojęcia nicości, które odgrywa w żydowskiej kabale kluczową rolę. Stawiam tezę, że myśl Scholema można określić mianem „dwóch wymiarów nicości”, odpowiadających pojęciom stworzenia i objawienia. Koncepcję nicości stworzenia omawiam na podstawie kabały Luriańskiej, będącej dla Scholema jednym z głównych źródeł inspiracji, zaś nicość 
objawienia odczytuję przez pryzmat twórczości Franza Kafki, której Scholem również poświęcił wiele uwagi. Pozwala to na oryginalną interpretację myśli Scholema, w której nicość nie konotuje nihilizmu, lecz zdradza znaczący potencjał produktywności.

\section{Słowa kluczowe}

judaizm, kabała, Gershom Scholem, nicość, Izaak Luria, Franz Kafka

\section{Abstract \\ Two Dimensions of Nothingness: Gershom Scholem and the Paradoxes of Jewish Mysticism}

The article analyzes Gershom Scholem's kabbalistic philosophy through the notion of nothingness, being a crucial notion of Jewish kabbalah. I argue that Scholem's thought might be called the "two dimensions of nothingness" which correspond to the concepts of creation and revelation. I analyze the nothingness of creation against the background of the Lurianic kabbalah whereas the nothingness of revelation is analyzed through the prism of Franz Kafka's literature. The result of the analysis is the original interpretation of Scholem's thought, in which nothingness fails to connote nihilism, having instead a substantial potential of productivity.

\section{Keywords}

Judaism, kabbalah, Gershom Scholem, nothingness, Isaac Luria, Franz Kafka 